\title{
Surface-Confined Two-Step Synthesis of the Complex (Ammine)(meso-tetraphenylporphyrinato)-zinc(II) on $\mathbf{A g}(111)$
}

\author{
Ken Flechtner, Andreas Kretschmann, Liam R. Bradshaw, Marie-Madeleine Walz, Hans-Peter Steinrück \\ and J. Michael Gottfried*
}

Universität Erlangen-Nürnberg, Lehrstuhl für Physikalische Chemie II, Egerlandstr. 3, 91058 Erlangen, Germany

\section{Supporting Information}

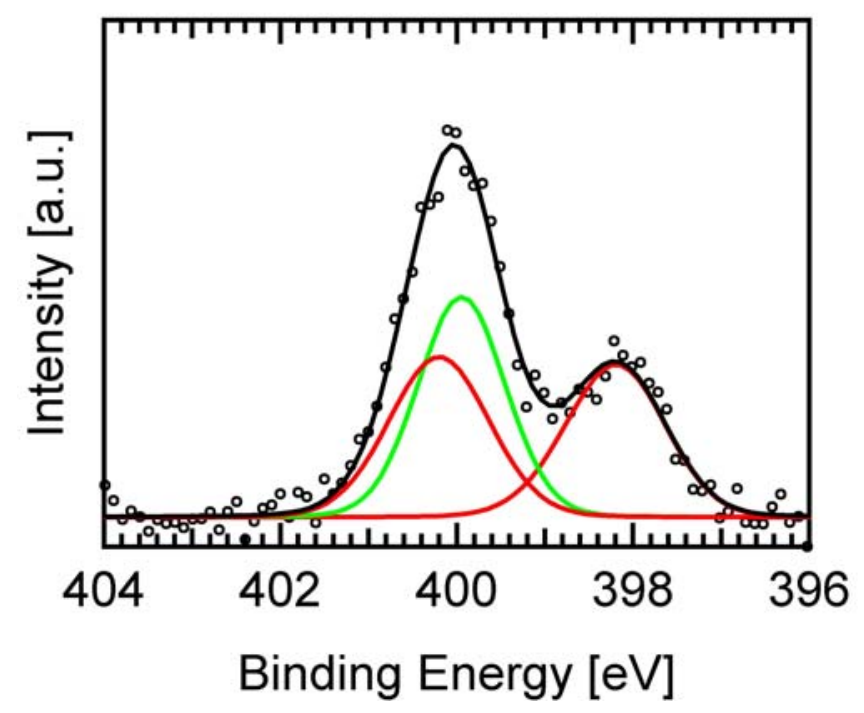

Figure S1: $\mathrm{N}$ 1s XP spectrum of $\mathrm{H}_{2} \mathrm{TPP}$ multilayers on $\mathrm{Ag}(111)$ at $140 \mathrm{~K}$ in the presence of an $\mathrm{NH}_{3}$ background pressure of $1 \times 10^{-8}$ mbar. Adsorption of $\mathrm{NH}_{3}$ is revealed by the increased signal around $400 \mathrm{eV}$. Signal deconvolution: red $-\mathrm{H}_{2} \mathrm{TPP}$, green - $\mathrm{NH}_{3}$, black - envelope. 


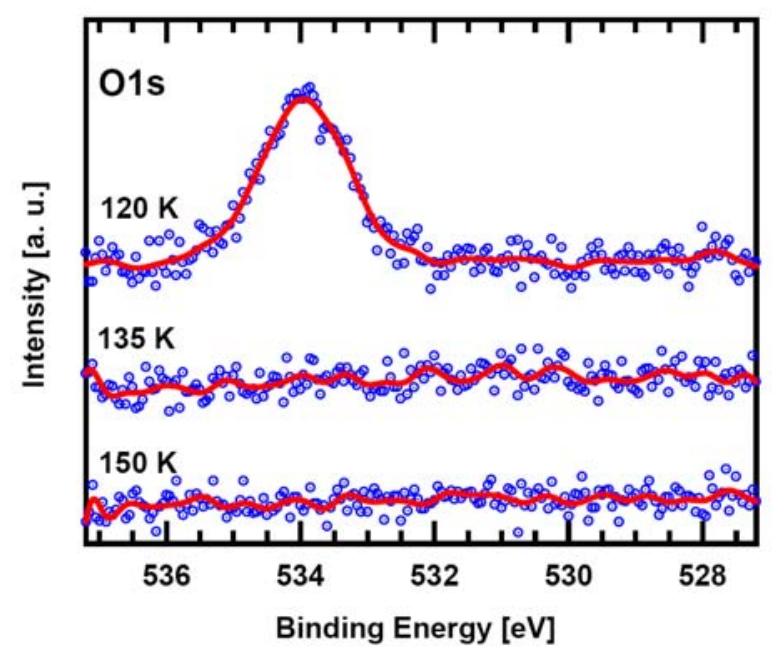

Figure S2: Temperature dependency of the adsorption of water (from the residual gas) on the ZnTPP monolayer after extended periods of time $(>2 \mathrm{~h})$ in the presence of an $\mathrm{NH}_{3}$ background pressure of $1 \times 10^{-8}$ mbar. At and above $135 \mathrm{~K}$, no adsorption of water (indicated by the signal at $534 \mathrm{eV}$ ) adsorbs on the $\mathrm{ZnTPP}$ layer, regardless of the presence of $\mathrm{NH}_{3}$.

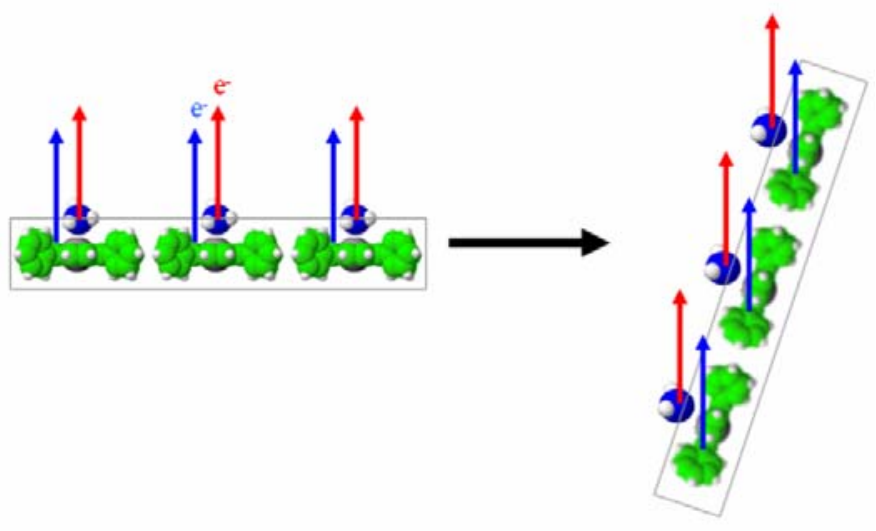

Figure S3: Detection of the N 1s photoelectrons in normal (left) and grazing geometry (right). For grazing detection, the electrons emitted from the porphyrin nitrogen atoms must pass through part of the porphyrin layer, which reduces the effective signal intensity relative to that of the $\mathrm{NH}_{3}$ related signal. 